\title{
Epidemiology of disabling neurological disease: how and why does disability occur?
}

\author{
Derick T Wade
}

Epidemiological research aims to establish the causes, mechanisms, and natural history of illness. It has traditionally focused on specific diseases, using data obtained from populations to investigate the factors related to the disease of interest. The relevant data will usually include some of the characteristics of the patient; the manifestation of the disease; the patient's history and social status; the patient's past and present environment; and the characteristics of other people without the disease. Analysis aims to establish the nature and strength of the interrelations between these factors and the occurrence of disease. In this way epidemiology has answered questions such as: Why does this disease occur? What causes it? What is likely to happen? How can we prevent disease or improve recovery?

Often epidemiological research will incidentally also answer the question, How common is this disease? Consequently a second, much more recent focus has been the use of epidemiological data on the frequency (incidence or prevalence) of diseases to plan the delivery of health services. This secondary analysis has tried to answer the questions: How many people will develop or have the disease? What services may be needed by patients with this disease? However, most of the data used come from studies designed to disentangle the causes or natural history of disease. Very few studies have set out to determine the need of the community for specific health services, not least because it is difficult to determine a patient's need for an intervention (defined as their ability to benefit from the intervention) from the information available.

More broadly, epidemiological research also "strives to develop a theoretical framework for the understanding of health experience". ${ }^{1}$ Disability is, for many people with neurological disease, an integral if not overwhelming part of their health experience. Therefore this review starts with a consideration of disease based epidemiology; the frequency of neurological disability; and the need for services. However, the information available relating to these topics is too poor to allow specific conclusions, and the bulk of this review considers a theoretical framework of illness, the predictions this theory makes, and some of the available evidence relating to these predictions.
Frequency of neurological disability

For disabling neurological disease, there is currently a major focus on planning appropriate services especially for common chronic diseases and their rehabilitation. This topic was reviewed 10 years ago, ${ }^{2}$ and epidemiological studies have been reviewed since in relation to various specific services..$^{3-7}$ There are several problems with using currently available epidemiological data to plan services and to estimate disability.

The first problem with using currently available disease based epidemiological studies is that patients with rare diseases such as tuberous sclerosis will often not have their problems specifically accounted for. ${ }^{8}$ Although each individual disease is rare, it is likely that the combined incidence and, more importantly, prevalence of these rare diseases is sufficient to make a major impact on health services. Furthermore, the epidemiology of many rare diseases is poorly researched.

Next, this disease based approach does not account for services needed for people presenting to medical services with a symptom for diagnosis. For example, the number of patients referred with "possible multiple sclerosis" probably exceeds the true incidence of multiple sclerosis by a factor of five. Although this has not been formally researched, data from routine clinical practice highlights the number of patients who have no clearcut diagnosis. ${ }^{910}$ None the less, patients with diagnostically uncertain problems, such as undiagnosed tremor, may be disabled and need disability services. ${ }^{11}$

Thirdly, using data on the epidemiology of the disease itself to study the epidemiology of (neurologically based) disability assumes reasonable information about the proportion of incident or prevalent cases who are in fact disabled (if disability is the interest) or who might benefit from services (if service planning is the interest). Such information is rarely, if ever, available. Establishing need, the ability to benefit from an intervention, is particularly difficult because: (a) there is limited evidence concerning the ability to benefit; and $(b)$ this requires an assessment by an experienced clinician.

Lastly, secondary analysis of epidemiological data does not easily allow calculation of the
Rehabilitation Centre, Abingdon Road Oxford OX1 4XD, UK D T Wade 
number of people needing a specific service such as advice on wheelchairs, or urodynamic investigations and advice on continence, or spasticity management. These important practical problems, which have important resource implications, arise as a relatively rare consequence of many separate diseases and have not been specifically studied.

Few if any studies have specifically focused on the nature or extent of disability within a specific disease, let alone specifically focusing on the incidence or prevalence of specific disabilities across several diseases. There are no useful studies allowing meaningful comparison of neurological disability between geographic areas, or over time, or between diseases.

Only one specific epidemiological point needs to be made in relation to neurological disability. Neurological disease or injury accounts for the vast majority of patients with severe disability. ${ }^{12-17}$ Specialists with training in neurology and disability are obviously needed to help manage this large and important population of patients who have specific problems not seen in patients with non-neurological diseases.

Otherwise much of the information relating to the traditional epidemiology of neurological disease has been reviewed in this series. More importantly the gaps in available data mentioned above cannot be filled with much accuracy until more systematic studies focusing on disability are undertaken. Therefore this review will not attempt to calculate the incidence or prevalence of neurological disability because any conclusions will be too uncertain to be useful.

\section{The topic of this review}

Instead this review will suggest to the reader that there is another important area awaiting epidemiological research. This area is analogous to the study of the causes of disease. It is the study of the mechanisms leading to disability, an area still awaiting appreciable systematic epidemiological research despite its recognition in the past. ${ }^{1}{ }^{18}$

This review will argue that investigations into the relations between disability and other areas is urgently needed and that traditional methods of epidemiological research would be very appropriate to investigate the nature and

The four levels of illness in the WHO ICIDH model

\begin{tabular}{|c|c|c|c|}
\hline Word & Level/system affected & Definition & Synonym \\
\hline Pathology & Organ or organ system & $\begin{array}{l}\text { Any abnormality of macroscopic, } \\
\text { microscopic, or biochemical } \\
\text { structure or function affecting } \\
\text { an organ or organ system }\end{array}$ & $\begin{array}{l}\text { Diagnosis or } \\
\text { disease }\end{array}$ \\
\hline Impairment & Organism & $\begin{array}{l}\text { Any abnormality of structure } \\
\text { or function of, or affecting, the' } \\
\text { whole body independent of } \\
\text { any specific environment }\end{array}$ & $\begin{array}{l}\text { Symptoms and } \\
\text { signs }\end{array}$ \\
\hline Disability & $\begin{array}{l}\text { Interaction between } \\
\text { organism and } \\
\text { environment (people } \\
\text { and objects)-that is, } \\
\text { behaviour }\end{array}$ & $\begin{array}{l}\text { Any change or restriction in a } \\
\text { patient's goal directed } \\
\text { behaviour or behavioural } \\
\text { repertoire, usually manifest } \\
\text { as dependence }\end{array}$ & $\begin{array}{l}\text { Functional } \\
\text { limitations }\end{array}$ \\
\hline Handicap & $\begin{array}{l}\text { Meaning attached to } \\
\text { behaviour by self and } \\
\text { others }\end{array}$ & $\begin{array}{l}\text { Any alteration in a patient's } \\
\text { status (position) in society } \\
\text { including alterations in roles }\end{array}$ & $\begin{array}{l}\text { Social } \\
\text { consequences }\end{array}$ \\
\hline
\end{tabular}

genesis of disability. These methods could and should be used to increase our understanding of the questions: How and why do some people become disabled whereas others do not? How many people need disability services? What is the natural history of disability?

The review has several limitations. Formal searching of the medical literature has not been undertaken. Identifying appropriate studies is difficult, because abstracts and computer indexes do not mention the presence or otherwise of information on disability. Moreover, this review concerns a form of epidemiological research that is not yet specifically recognised. Next, I have a biased interest in neurological disability and believe that the subject is not given sufficient attention or resources. Consequently most of the studies referred to have been found in the pursuit of that interest; they have been selected because they relate to the hypotheses being put forward. There will be gaps and may be important omissions.

The review puts forward a thesis for debate and does not intend to prove the thesis absolutely. The thesis put forward is that the model of illness developed within the field of rehabilitation medicine should now be tested against empirical epidemiologically based data. The model makes certain predictions about the factors which may impact on disability and the relative importance of those factors. These predictions can be tested. This review will supply some relevant data but better studies are needed to consolidate and improve the model.

\section{World Health Organisation Model of Impairment, Disability and Handicap, and terminology}

The traditional epidemiological approach to disease both depended on and itself helped to develop a new model of illness. It drew attention to the importance of infectious agents, social factors, environmental poisons, etc in the genesis of disease. Before epidemiological research, disease was often mysterious and misunderstood. Unfortunately disability is still often misunderstood, and debates about the definitions of disability and rehabilitation can be endless, and often complicate and dominate discussion.

Therefore, before reviewing the relevant data, it is vital to have a clear understanding of the framework involved when discussing disability, and to agree the terminology. This review uses concepts and definitions which are commonly referred to as the World Health Organisation model of Impairment, Disability and Handicap (WHO ICIDH). ${ }^{19-25}$ This model can be derived using a systems approach to analyse illness (defined here as the personal experience of disease), and it divides illness into four hierarchical levels (see table and figure). The model has a long, largely unpublished history ${ }^{18-21}$ and is still largely theoretical. ${ }^{25}$ One vital role of future epidemiological research will be to validate this model, or to alter and improve it. 
WHO ICIDH model of illness. Arrows on left refer to generally accepted relations. Arrows on right and dashed arrows are less generally accepted. Strength of relations unknown.

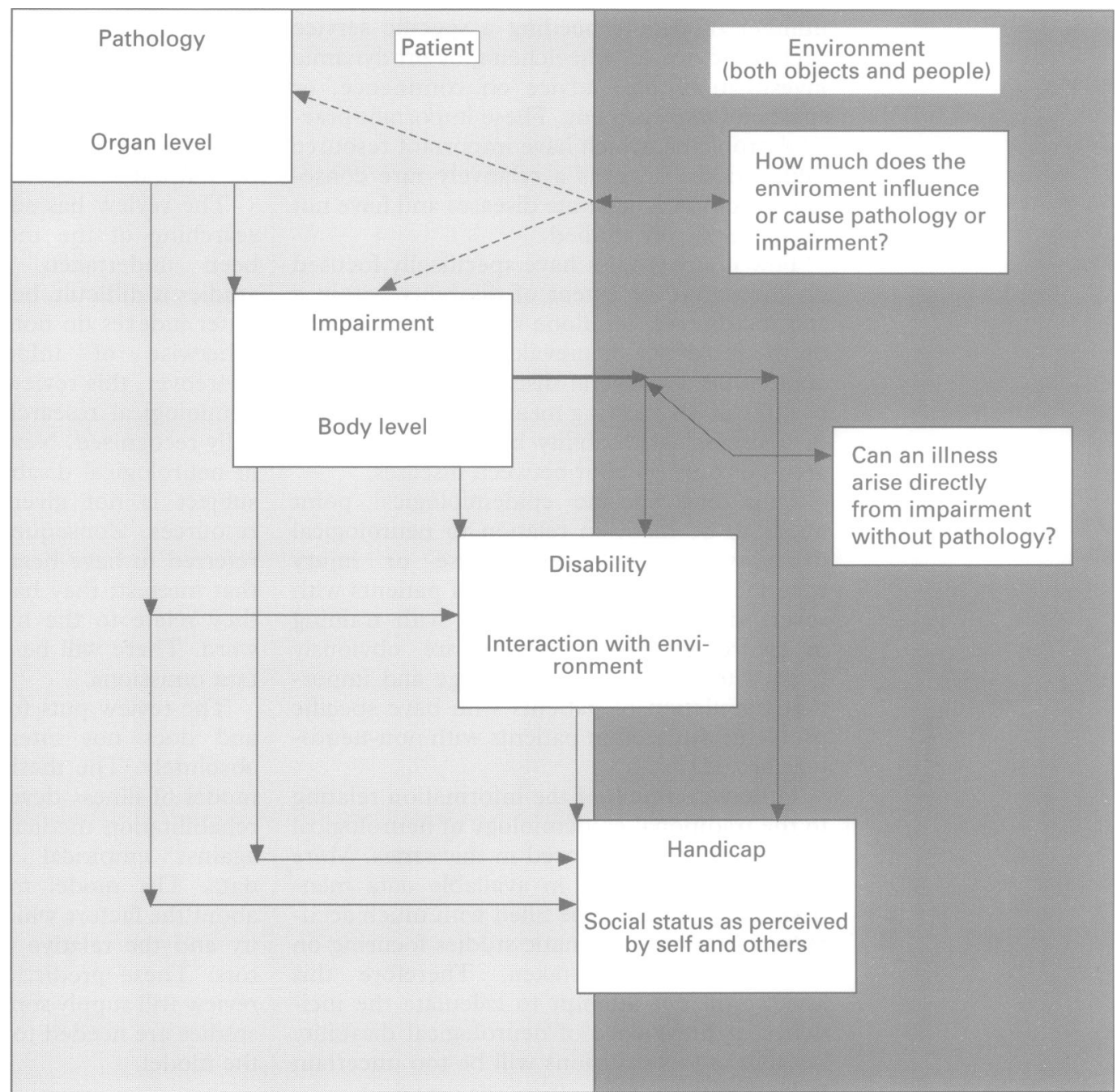

The terminology and definitions given in the table are not identical to those used in the official document. ${ }^{19}$ They are sufficiently close to be acceptable but some points must be remembered. Firstly, it is probably best to conceive of or refer to "changes at the level of" handicap, rather than handicap (and similarly for the other levels). Next, there is no good word for normal except the absence of (for example) impairment. Thirdly, many people will use these words in other ways, usually in other contexts. The definitions given here are all referred to in the context of illness.

The WHO ICIDH model emphasises that disability is best considered as a change in or restriction on a person's behaviour. ${ }^{22-24}$ Disability is not synonymous either with being in a wheelchair or with being dependent. Within this model rehabilitation is synonymous with "the management of neurological disability" and it can be defined as: "an educational, reiterative, problem solving process which focuses on disability and aims to maximise the patient's social role functioning and to minimise the somatic and emotional distress experienced by both patient and family." Within this definition it must be recognised that (a) one aim of rehabilitation is to minimise handicap, not to minimise disability and (b) that the other aims relate to stress and distress experienced by patients and families. The main objectives of rehabilitation for the patient are to maximise his or her behavioural repertoire; to optimise the environment; and to help with emotional distress.

Epidemiological research is needed to consider several important questions. Are the concepts and definitions supported by the empirical data? What are the interrelations between the four levels? ${ }^{25}$ How does distress of the family and patient relate to disability (or impairment)? What interventions are most likely to assist with the aims and objectives of rehabilitation? Some studies providing data relating to some of these questions will be reviewed.

\section{Nature and genesis of disability}

The WHO ICIDH model is based on the premise that four separate but related systems may be affected within any illness: the organ; the body (a collection of organs); the person interacting with the environment; and the person's position within their own social network. It was assumed within the original model that there is a relatively straight pathway from pathology through impairment to disability and on to handicap (arrows on the left in the figure). ${ }^{18-21}$ However, it was recognised that sometimes the chain of causation could jump one level. The possibility of jumping from pathology to handicap was not considered. The possibility than some illness may arise pri- 
marily at the level of impairment or even at the level of disability has also not been formally raised (see figure).

Epidemiological research could be used to investigate the nature and genesis of disability and handicap just as it has previously been used to investigate the nature and genesis of disease. In fact few studies have specifically investigated the links between pathology, impairment, disability, and handicap in a formal way. Most of the information available comes from studies which focused on other matters.

\section{Pathology and impairment}

The model predicts a relatively close relation between the impairments seen or experienced and the underlying pathological process, both in quality (that each pathological lesion will be associated with specific impairments) and in quantity (that more severe disease will be associated with impairments of greater severity or more impairments). However, the model also predicts that pathology may occur without impairment and that impairment may possibly occur without pathology.

The traditional medical diagnostic approach depends on a relatively close qualitative link between impairments (symptoms and signs) and the underlying disease (pathological process). However, although the link between pathological process and impairment is relatively close and invaluable in making a diagnosis, it is not absolute. Examples of this weak link include patients without recorded symptoms found after death to have the pathological changes of multiple sclerosis; and the large size achieved by some malignant brain tumours before their clinical presentation.

The links between impairment and pathology are well documented and form the basis of all medicine. Qualitatively impairments can be used to allocate stroke patients into broad diagnostic groups locating the area of cerebral infarction. ${ }^{26}$ Quantitatively there is a link between the volume of brain loss after stroke and acute impairments. ${ }^{27}$ In multiple sclerosis relatively strong links have been found between total lesion load shown on MRI and the extent of cognitive impairment (Moller et $a l^{28}$ and review by $\mathrm{Rao}^{29}$ ).

With more sensitive techniques for detecting pathology, the weaknesses in the links between pathological processes and impairments are becoming more apparent. It is now possible to detect the pathology of Huntington's chorea using genetic tests before any clinical manifestations are apparent. ${ }^{30}$ The use of MRI to investigate patients with single symptomatic episodes of (for example) optic neuritis can demonstrate more widespread pathology. ${ }^{31}$ Investigation of elderly people presenting with epilepsy will sometimes disclose silent cerebral infarction, ${ }^{32}$ and clinically silent episodes of cerebral infarction are common. ${ }^{33} 34$

The relation between specific impairments and specific lesion location also needs much further research, and it is possible that many neurologists and psychologists place too much weight on the association between specific impairments and specific lesion locations. For example, it is common clinical practice in management of head injury to equate poor performance on the Wisconsin card sorting test (an impairment) with frontal lobe damage (a pathological lesion). The minimal evidence available suggests that there may be little or no linkage between poor performance on this test and specific locations of cerebral damage ${ }^{35}$ (although there may be ${ }^{36}$ ). Similarly, it is difficult to determine any unique or central area of damage underlying aphasia. ${ }^{37}$

It may be concluded that some predictions are upheld: the qualitative and quantitative links between pathology and impairment are reasonable and pathology may occur without impairment. However, the strength of these links has not be studied closely in many situations, and caution is needed when attributing impairments to pathology demonstrated by modern sensitive investigations. More caution is needed when attributing specific impairments to specific lesion locations. Thus although general associations exist between impairments and lesion location, much further detailed research into the relation between pathology and impairment is needed, including studies of the strength of any associations between impairment and pathology (for example, their specificity and sensitivity). It would also be of interest to discover what factors affect the development of impairments with pathology; why are some large lesions asymptomatic?

\section{Pathology and disability}

The WHO ICIDH model predicts that the links between pathology and disability are not very close in either direction. In this context it is worth remembering that disability is manifest most obviously as dependence, and that providing care to alleviate dependence requires resources.

Despite this prediction, the current use of diagnosis related groups (DRGs) (healthcare resource groups, HRGs in Britain) as a means of defining resource groups is based, in part at least, on the untested assumption that the resources used by a patient are related to pathological diagnosis. In fact it is common experience that use of health resources is dominated by the need to provide care, not by treatments or investigations specific to the pathology. For this reason, if no other, there is an urgent need to investigate the relation between pathological diagnosis and disability. At present there are no studies comparing levels of disability between different diseases, and none explicitly comparing specific disabilities between diseases. Moreover, one study on selected inpatients has shown that health resources used by disabled people are not related to diagnosis. ${ }^{38}$

There are a few specific examples of pathology which are clearly and closely related to specific disabilities. The best example is spinal cord injury, in which the lesion and, more 
importantly, its location define quite repeatably the disabilities experienced. However, there are few other instances of such a close relation, and in most cases it is likely that the pattern and extent of disability is only weakly related, if at all, to diagnosis. Unless (or until) a close relation is shown between pathological diagnosis and resource use, it would be sensible to develop disability related groups as a means of justifying or giving resources.

The more interesting relation to investigate is that between the extent of pathology and the nature and extent of disability within a group of patients with the same diagnosis (pathologically homogenous). For many diseases, such as Parkinson's disease, it is not directly possible to quantify the extent of pathology in life. If it is assumed that pathology in Parkinson's disease increases with duration of disease then there may be a reasonable link between extent of pathology and level of disability, but this assumption may not be valid. In multiple sclerosis there are now several studies investigating the link between changes seen on MRI and disability. ${ }^{39-41}$ Although the results are not all in agreement, it can be concluded that any link between the extent of multiple sclerosis pathology and disability is relatively weak. In stroke the few studies investigating the relation between CT changes and longer term levels of disability have found at best a weak link between the volume or location of a stroke and the resultant long term disability. ${ }^{42} 43$

At present the prediction of weak links if any between the type of pathological process (diagnosis) and associated disability is untested because the epidemiological evidence is almost non-existent. The very few studies of patients with a single diagnosis which provide data on the link between the extent of pathology and the level of disability support the hypothesis that there may be a weak statistical link in groups of patients, but in an individual patient the link is not clinically useful.

\section{Impairment and disability}

The model predicts a relatively close relation between impairment and disability, although this relation will be complicated by several other influences. Two are discussed below and the third, the environment, is discussed later.

The first complicating factor is that patients may learn to achieve their behavioural goals in other ways when an impairment is present. For example, someone can learn to write using their left hand if they lose their right hand; someone can learn to walk despite a stiff (or even absent) leg; aids, equipment and other environmental changes can allow someone to have more independent behaviours despite unchanging impairment; and new goals and behaviours may develop in place of old ones (for example, someone may develop new work skills or new hobbies). Therefore the relation between a specific impairment and a specific disability might vary both over time, as adaptation occurs, and between patients dependent on their motivation, adaptability, and opportunities. Only epidemiological research investi- gating large groups and collecting all relevant ancillary data can illuminate this problem successfully.

The second and even more important feature is that it is rare for a single impairment to be present on its own and it is unusual for a single impairment to be the only or major cause of a specific disability. ${ }^{25}$ Normal behaviour depends on the integrated functioning of many skills. Disruption of one skill alone may sometimes lead directly to a single specific disability but this will be rare. More usually disruption of several skills will be needed to cause a disability. Indeed, sometimes the impairment might be compensated for under most conditions and disability will only be disclosed under stress. For example, it has been shown that standing balance using a prosthesis after amputation is made worse by a stressful cognitive task in the early stages of rehabilitation. ${ }^{44}$ Thus a specific disability might arise in many ways from different combinations of many different impairments and, conversely, a single impairment may lead to or be an influence on several disabilities. ${ }^{25}$

To an extent this complexity has been shown by the multivariate prognostic equations developed (for example) in stroke research ${ }^{45}$; in most studies and equations there are two to four early impairments which relate to later disability. These studies have investigated the prognostic relation between current impairment and future disability. Concurrent comparisons are less common but do also show that several impairments relate to the level of disability. ${ }^{46-53}$ Sometimes the combination of impairments will arise from several diseases (the essence of geriatric medicine).$^{54}$

None the less, studies have found the expected relations between the presence or severity of a single impairment and the severity of disability. In the acute phase after stroke there is an unsurprising relation between the degree of motor loss and the extent of disability. ${ }^{46}$ Other studies have shown the expected positive relations between strength of various leg muscles and gait speed ${ }^{47} 48$ and between the degree of motor loss after stroke and arm function. ${ }^{49}$ The specific impairment of tremor is associated with a higher level of dependence in activities of daily living (ADL). ${ }^{11}$ Mobility disability in spinal cord injury is closely related to motor impairment. 55

In relation to neurological disability, epidemiological studies disclose one important but often neglected fact: many patients with disabling neurological disease have considerable impairment of both cognitive skills and emotional control. Up to half of all patients with stroke have problems with memory and other cognitive skills ${ }^{567}$; up to half of all patients with multiple sclerosis have measurable cognitive losses ${ }^{29}$; cognitive losses occur in motor neuron disease, albeit at a relatively minor level, ${ }^{58}$ and in at least $20 \%$ of patients with Parkinson's disease ${ }^{59}$; and they are an important feature in many other pathalogical states, such as Huntington's chorea, Friedreich's ataxia, muscular dystrophy, and (obviously) head injury. The frequency of 
changes in emotional control or state has been less well studied, but it is likely to be important in stroke, ${ }^{60}$ multiple sclerosis, ${ }^{61}$ motor neuron disease $\mathrm{e}^{58}$, head injury, and many other situations.

These epidemiological findings are important for two reasons. Rehabilitation is concerned with altering behaviour through learning and adaptation. This depends on the patient being able to learn, and it is often their very ability to learn and adapt that is compromised by the disabling disease. Moreover, most behaviour is goal directed, and changes in emotional state may have a major influence on behaviour and adaptability. There is minor, weak evidence that altering depression may reduce disability. ${ }^{6263}$

Unfortunately many people have a very mechanistic view of disability and ignore or overlook the importance of these "hidden" impairments. For example, most service provision refers to patients with "physical disability". The more accurate phrase would be "patients with motor impairment" but this grouping ignores the reality that motor impairment is rarely the major factor causing disability.

It may be concluded that the evidence supports the general relations expected between impairment and disability. However, they are only apparent either when the level of impairment is extreme or in specific diseases. The importance of concurrent relations between impairment, especially combinations of impairment and disability, has yet to be explored in a systematic manner. Hopefully further epidemiological research will eventually convince service planners that emotional and cognitive impairments are central to understanding most disability and that "physical disability" does not exist.

\section{Disability, handicap, and the \\ environment}

Because disability refers to the patient's interaction with his or her environment, this model predicts that environmental factors will have a significant influence on disability and an even greater influence on handicap. The extent of this influence on disability will be moderate, probably less than the influence of the patient's impairments. A patient's position in society is determined primarily by how other people interpret and perceive role performance and so this model predicts that handicap will be greatly influenced by a patient's social environment.

The presence of HIV infection gives an example of the importance of social factors in determining handicap, and it also shows that a pathological process can cause handicap directly. A person found on incidental testing to have HIV infection will not have any impairment or disability. However, once the fact of infection is known to others it will affect personal relations, housing, employment, etc. The handicap is determined by the attitude and perception of other people.

There are few studies appertaining to this area. Observational studies have suggested that people who live alone are more independent. ${ }^{64}$ but it is uncertain whether this relation reflects selective loss from the study of more dependent people into institutional care or the effects of necessity. There are very few studies of the relation between environmental adaptations and disability, even at the level of simple aids such as ankle-foot orthoses. ${ }^{65}$ It is worth noting that independence in some activities such as stair climbing may be important in a British context but of little importance in parts of the world such as Australia, where most accommodation is single storey.

Identifying the influences on handicap will be difficult, not least because the definition and measurement of handicap continues to be extremely difficult. ${ }^{66}$ Moreover, it is likely that many influences will lie well outside the remit of health services. Consequently it is difficult to cite studies. One study has investigated the relation between one dimension of handicap and disability, finding (as predicted) that financial resources alleviate handicap. ${ }^{67}$ Another study investigated the factors influencing handicap caused by vertigo. ${ }^{68}$ This study, which is probably more accurately considered as a study of disability, started to disentangle the relations between symptoms (vertigo), other secondary impairments (fear, emotional distress), and restriction of activities. A study on the factors affecting social functioning after stroke also showed the complexity of interrelations between emotional state, age, intelligence, sex, and premorbid interests..$^{69}$

Therefore the major conclusion to be drawn is that much further research is needed to provide data to allow the concept of handicap to be tested empirically; to determine the relation between a patient's behavioural repertoire and the level of handicap; to investigate the relation between specific disabilities and handicap in different cultures and societies; and to determine how other environmental factors relate to disability and handicap. For example, altering regulations related to disability allowances might reduce or increase handicap, ${ }^{25}$ and empirical data would help guide decisions.

\section{Illness without disease}

Using a systems analytical approach to derive the WHO ICIDH model shows that not all illness has an underlying pathology. If the hypothesis that the model encompasses four separate systems, then systems theory would predict that illness may emerge at any level without a specific abnormality at a lower level. In other words it is possible that not all "neurological disability" arises from neurological disease.

In fact this is a well recognised phenomenon. In our own local "young disabled unit" $5 \%$ to $10 \%$ of patients in wheelchairs do not have any diagnosed neurological (or specific psychiatric) disease (unpublished observations). More generally it is well reported that patients may present with neurological impair- 
ments and disability and yet have no demonstrable neurological pathology. ${ }^{70}$

Furthermore, it has long been recognised that external stress such as bereavement (a change in personal environment) is associated with increased mortality and that depression (an impairment) is associated with altered immunity (a pathological state).$^{71}$ Interactions between the nervous system and changes in the immune system have been reviewed recently. ${ }^{72}$ Poverty is associated with a higher level of mortality, ${ }^{7374}$ again showing a possible link "in reverse" with factors at the level of handicap in some way causing pathological abnormalities (and hence death or later neurological disability).

Some specific common diagnoses may in fact represent illness arising at the level of impairment. Headache and the disability and handicap associated with it may well be the commonest example of an illness without a specific underlying pathology. Population based studies have generally failed to substantiate any specific types of headache ${ }^{7576}$ and it is possible that any reported biochemical or other changes at the level of pathology associated with migraine are simply epiphenomena, occurring as a result of the impairment. The development of frozen shoulder after myocardial infarct is another example of a secondary pathology. Other conditions that may well represent illnesses arising at the level of impairment (with possible contributions from levels of disability and handicap) include chronic fatigue syndrome; situational anxiety; posttraumatic stress disorder; and pseudoepilepsy. It is of interest that an intervention at the level of impairment, cognitive behavioural treatment, is effective at reducing the illness experienced in chronic fatigue syndrome ${ }^{77}$; this adds weight to the supposition that this illness has no primary pathological process.

The prediction from the WHO ICIDH model that in some instances illness may arise primarily at the level of impairment is at least plausible. The mechanisms and the relation to changes at the level of pathology are still to be determined. Sometimes the cause may lie within the patients, whereas in other cases external stressors may be responsible. Epidemiological research might help validate this cause of disability and handicap, and also might help to foster rational management of the many patients with these disorders.

\section{Conclusions}

There is an urgent need for research into the mechanisms of disablement and traditional epidemiological methodology would be an effective approach. The current information is sparse, but does support the hypothesis that the links between pathology, impairment, and disability are weak in individual patients, although there are some important exceptions (spinal cord injury). There may well be cases of patients with disability and impairment but no pathology. There is specifically no information on the relation between combinations of impairments and the resultant disability.
There is little information on the importance (or otherwise) of impaired cognition and emotional control in the generation or alleviation of disability. There is little information on how altering the physical, social, and legal environment might affect handicap. A clear understanding of the mechanisms underlying disability might allow a more rational, efficient, and cost effective approach to the management of patients with neurological disability. Research into neurological disability is needed urgently, using traditional epidemiological methods to unravel the extremely complex interrelations.

1 Wood PHN, Badley EM. Contribution of epidemiology to health care planning for people with disabilities. In: Granger CV, Gresham GE, eds. Functional assessment in rehabilitation medicine. London: Williams and Wilkins, rehabilita

2 Wade DT, Langton-Hewer R. Epidemiology of some neurological diseases with special reference to work load on the NHS. International Disability Studies 1986;8:129-37.

3 Wade DT. Designing district disability services-the Oxford experience. Clinical Rehabilitation 1990;4:147-58.

4 Wade DT. Stroke (acute cerebrovascular disease). In: Stevens A, Raftery J, eds. Health care needs assessment. The epidemiologically-based needs assessment reviews. Oxford: Radcliffe Medical Press, 1994.

5 Wade DT. Policies on the management of patients with head injuries: the experience of the Oxford Region. Clinical Rehabilitation 1991;5:141-55.

6 British Society of Rehabilitation Medicine. A working party report on multiple sclerosis. London: Royal College of report on multiple
Physicians, 1993.

7 Brown S, Betts T, Chadwick D, Hall B, Shorvon S. An epilepsy needs document. Seizure 1993;2:91-103.

8 Leone M, Bottacchi LM, D'Alessandro G, Kustermann S. Hereditary ataxias and paraplegias in Valle d'Aosta, Italy: a study of prevalence and disability. Acta Neurol Scand 1995;91:183-7.

9 Perkin GD. An analysis of 7836 successive new out-patient referrals. F Neurol Neurosurg Psychiatry 1989;52:447-51.

10 Hopkins A, Menken M, DeFreise G. A record of patient encounters in neurological practice in the Unite

11 Louis ED Marder K Cote Ir Psychiary 1989;52.436-8. of shaking in persons 65 years of age and older: diagnostic of shaking in persons 65 years of age and older: diagno

12 Knight R, Warren MD. Physically disabled people living at home: a study of numbers and needs. Report on health and social subjects 13. London: Department of Health and social subjects 13. London: Dep

13 Hanley J, McAndrew L. A survey of the younger chronic sick and disabled in the community in the Lothian region. International Disability Studies 1987;9:74-7.

14 Martin J, Meltzer H, Elliott D. The prevalence of disability among adults. Surveys of disability in Great Britain. Report 1. London: Office of Population Censuses and Surveys; HMSO, 1988.

15 Harrison J. Severe physical disability. Responses to the challenge of care. London: Cassell Educational, 1987.

16 Royal College of Physicians. The young disabled adult. London: Royal College of Physicians, 1986.

17 Prouse P, Ross-Smith K, Brill M, Singh M, Brennan P, Frank A. Community support for young physically handFrank A. Community support for young physical

18 Nagi S. An epidemiology of disability among adults in the USA. MMFQ/Health and Society 1976;439-67.

19 World Health Organisation. International classification of impairments, disabilities, and handicaps. Geneva: WHO, 1980.

20 Duckworth D. The need for a standard terminology and classification of disablement. In: Granger CV, Gresham $\mathrm{GE}$, eds. Functional assessment in rehabilitation medicine. London: Williams and Wilkins, 1984.

21 Granger CV. A conceptual model for functional assessment. In: Granger CV, Gresham GE, eds. Functional assessment in rehabilitation medicine. London: Williams and Wilkins, 1984

22 Wade DT. Neurological rehabilitation. In: Kennard C, ed. Recent advances in clinical neurology. London: Churchill Livingstone, 1990.

23 Badley EM. An introduction to the concepts and classifications of the international classification of impairments, tions of the international classification of impairments,
disabilities and handicaps. Disabil Rehabil 1993;15: disabilities

24 Wade DT. Measurement in neurological rehabilitation. Oxford: Oxford Medical Publications, 1992.

25 Whyte J. Toward a methodology for rehabilitation research. Am F Phys Med Rehabil 1994;73:428-35.

26 Bamford J, Sandercock P, Dennis M, Warlow C. Classification and natural history of clinically identifiable subtypes of cerebral infarction. Lancet 1991;337:1521-6.

27 Allen CMC. The accurate diagnosis and prognosis of acute stroke. Correlation of clinical features with computed tomographic appearances and functional outcome. MD thesis, 
University of Cambridge, 1985.

28 Moller A, Wiedemann G, Rohde U, Backmund H, Sonntag A. Correlates of cognitive impairment and depressive mood disorder in multiple sclerosis. Acta Psychiatr Scand 1994;89:117-21.

29 Rao SM. Neuropsychology of multiple sclerosis. Current Opinion in Neurology 1995;8:216-20.

30 Goldberg YP, Telenius H, Hayden MR. The molecular genetics of Huntington's disease. Current Opinion in Neurology 1994;7:325-32.

31 Morrisey SP, Miller DH, Kendall BE, et al. The significance of brain magnetic resonance imaging abnormalities at presentation with clinically isolated syndromes suggestive of multiple sclerosis. Brain 1993;116:135-46.

32 Roberts RC, Shorvon SD, Cox TCS, Gilliat RW. Clinically unsuspected cerebral infarction revealed by computed tomography scanning in late onset epilepsy. Epilepsia 1988;29:190-4.

33 Kase CS, Wolf PA, Chodosh EH, Zacker HB, Kelly-Hayes $M$, Kannel WB, et al. Prevalence of silent stroke in patients presenting with initial stroke: the Framingham study. Stroke 1989;20:850-2.

34 Jorgenson HS, Nakayama H, Raaschou HO, Gam J, Olsen TS. Silent infarction in acute stroke patients. Prevalence, localisation, risk factors, and clinical significance: the Copenhagen stroke study. Stroke 1994;25:97-104.

35 Anderson SW, Damasio H, Jones RD, Tranel D. Wisconsin card sorting test as a measure of frontal lobe damage. $₹$ Clin Exp Neuropsychol 1991;13:909-22.

36 Arnett PA, Rao SM, Bernardin L, Grafman J, Yetkin FZ, Lobeck L. Relationship between frontal lobe lesions and Lobeck L. Relationship between frontal lobe lesions and
Wisconsin card sorting test performance in patients with Wisconsin card sorting test performance in pati
multiple sclerosis. Neurology 1994;44:420-5.

37 Willmes K, Poeck K. To what extent can aphasic syndromes be localised? Brain 1993;116:1527-40.

38 Rondinelli RD, Murphy JR, Wilson DH, Miller CC. Predictors of functional outcome and resource utilisation in inpatient rehabilitation. Arch Phys Med Rehabil 1991; 72;447-53.

39 Thompson AJ, Kermode AG, MacManus DG, et al. Patterns of disease activity in multiple sclerosis: clinical and magnetic resonance imaging study. $B M F 1990 ; 300$ : 631-4.

40 Khoury SJ, Guttmann CRG, Orav EJ, et al. Longitudinal MRI in multiple sclerosis: correlation between disability and lesion burden. Neurology 1994;44:2120-4.

41 Filippi M, Paty DW, Kappos L, et al. Correlations between changes in disability and T2-weighted brain MRI activity in multiple sclerosis: a follow-up study. Neurology 1995; 45:255-60

42 Miller LS, Miyamoto AT. Computed tomography: its potential as a predictor of functional recovery following stroke. Arch Phys Med Rehabil 1979;60:108-9.

43 Henon H, Godefroy O, Leys D, Mounier-Vehier F, Lucas $\mathrm{C}$, Rondepierre $\mathrm{P}$, et al. Early predictors of death and disability after acute cerebral ischaemic event. Stroke 1995;26:392-8.

44 Geurts ACH, Mulder TW, Nienhuis B, Rijken RAJ. Dualtask assessment of reorganisation of postural control in persons with lower limb amputation. Arch Phys Med Rehabil 1991;72:1059-64.

45 Gladman JRF, Harwood DMJ, Barer DH. Predicting the outcome of acute stroke: prospective evaluation of five outcome of acute stroke: prospective evaluation of five multivariate models and comparison with simple
ods. $\mathcal{F}$ Neurol Neurosurg Psychiatry 1992;55:347-51.

46 Wade DT, Langton-Hewer R. Functional abilities after stroke: measurement, natural history and prognosis. $\mathcal{f}$ Neurol Neurosurg Psychiatry 1987;50:177-82.

47 Bohannon RW. Selected determinants of ambulatory capacity in patients with hemiplegia. Clinical Rehabilitation 1989;3:47-53.

48 Bendall MJ, Bassey EJ, Pearson MB. Factors affecting walking speed of elderly people. Age Ageing 1989;18: 327-32.

49 Parker VM, Wade DT, Langton-Hewer R. Loss of arm function after stroke: measurement, frequency, and recovery. International Rehabilitation Medicine 1986;8: recover $69-73$.

50 Cockburn J, Smith PT, Wade DT. Influence of cognitive function on social, domestic and leisure activities of com- munity-dwelling older people. International Disability Studies 1990;12:169-72

51 Farmer JE, Eakman AM. The relationship between neuropsychological functioning and instrumental activities of daily living following acquired brain injury. Applied Neuropsychology 1995;2:107-15.

52 Stubgen JP, Lahouter A. Limb girdle muscular dystrophy: weakness and disease duration as predictors of functional impairment. Muscle Nerve 1994;17:873-80.

53 Cornwall A. The relationship of phonological awareness, rapid naming, and verbal memory to severe reading and spelling disability. Fournal of Learning Disability 1992;25: 532-8.

54 Collen FM, Wade DT. Residual mobility problems after stroke. International Disability Studies 1991;13:12-15.

55 Waters RL, Adkins R, Yakura J, Vigil D. Prediction of ambulatory performance based on motor scores derived from standards of the American Spinal Injury Association. Arch Phys Med Rehabil 1994;75:756-60.

56 Tatemichi TK, Desmond DW, Mayeux R et al. Dementia after stroke: baseline frequency, risks, and clinical features in a hospitalised cohort. Neurology 1992;42: 1185-93.

57 Wade DT, Skilbeck C, Langton-Hewer R. Selected cognitive losses after stroke: frequency, recovery and prognostic importance. International Disability Studies 1989;11:34-9.

58 Worthington A. Psychological aspects of motor neurone disease: a review. Clinical Rehabilitation 1996;10:185-94.

59 Brown RG, Marsden CD. How common is dementia in Parkinson's disease? Lancet 1984;2:1262-5.

60 House A Depression after stroke BMF 1987;294:76-8.

61 Minden SL, Schiffer RB. Affective disorders in multiple sclerosis. Review and recommendations for clinical research. Arch Neurol 1990;47:98-104.

62 Lipsey JR, Robinson RG, Pearlson GD, Rao K, Price TR. Nortriptyline treatment of post-stroke depression: a double blind study. Lancet 1984;1:297-300.

63 Reding MJ, Orto LA, Winter SW, Fortuna IM, Ponte PD, McDowell FH. Anti-depressant therapy after stroke. A double-blind trial. Arch Neurol 1986;43:763-5.

64 Belcher SA, Clowers MR, Cabanayan AC, Fordyce WE. Activity patterns of married and single people after stroke. Arch Phys Med Rehabil 1982;63:308-12.

65 Lehmann JF, Condon SM, Price R, deLateur BJ. Gait abnormalities in hemiplegia: their correction by ankleabnormalities in hemiplegia: their correction by ankle-

66 Badley EM.The genesis of handicap: definition, models of disablement, and role of external factors. Disability and Rehabilitation 1995;17:53-62

67 McDonough PA, Badley EM, Tennant A. Disability, resources, role demands and mobility handicap. Disability and Rehabilitation 1995;17:159-68.

68 Yardley L, Putman J. Quantitative analysis of factors contributing to handicap and distress in vertiginous patients: a questionnaire study. Clinical Otolaryngol 1992;17: $231-6$.

69 Wade DT, Legh-Smith J, Hewer RL. Depressed mood after stroke. A community study of its frequency. $\mathrm{Br} \mathcal{F}$ Psychiatry 1987;151:200-5.

70 Ron MA. Somatisation in neurological practice. $f$ Neurol Neurosurg Psychiatry 1994;57:1161-4.

71 Herbert TB, Cohen S. Depression and immunity: a metaanalytic review. Psychol Bull 1993;113:472-86.

72 Ader R, Cohen N, Felten D. Psychoneuroimmunology: interactions between the nervous system and the immune system. Lancet 1995;345:99-103.

73 Phillimore P, Beattie A, Townsend P. Widening inequality of health in northern England, 1981-91. BMF 1994;308: 1125-8.

74 Smith GD. Income inequality and mortality: why are they related? BMf 1996;312:988-9.

75 Diehr P, Diehr G, Koepsell T, Wood R, Beach K, Wolcott $B$, Tompkins RK. Cluster analysis to determine headache types. Fournal of Chronic Disease 1982;35:623-33.

76 Ziegler DK, Hassanein RS, Couch JR. Headache syndromes suggested by statistical analysis of headache dromes suggested by statistical analys

77 Sharpe M, Hawton K, Simkin S, et al. Cognitive behaviour therapy for the chronic fatigue syndrome: a randomised therapy for the chronic fatigue syndrom
controlled trial. $B M \mathcal{F} 1996 ; 312: 22-6$. 